\title{
Opportunities and challenges in school-based sex and sexual health education in Nepal
}

\author{
Acharya DR ${ }^{1}$, Van Teijlingen ER ${ }^{2}$, Simkhada $\mathbf{P}^{3}$
}

${ }^{1}$ Project Assistant, Epidemiology Group, Section of Population Health, University of Aberdeen, ${ }^{2}$ Reader in Population Health, University of Aberdeen, ${ }^{3}$ Lecturer in International Health, Section of Population Health, University of Aberdeen Scotland, UK.

\begin{abstract}
This article identifies and addresses opportunities for and challenges to current school-based sex and sexual health education in Nepal. Key literature searches were conducted of electronic databases and relevant web-sites, furthermore personal contact with experts and the hand searching of key journals was included. The review of this literature generated the following challenges: Limitations to teaching including lack of life skill-based and human right-based approach, inappropriate teaching aid and reliance on conventional methods, existing policy and practice, parental/community support, and lack of research into and evaluation of sex education. Diverse methodology in teaching, implementation of peer education programme, partnership with parents, involvement of external agencies and health professionals, capacity building of teachers, access to support and service organisation, and research and evaluation in sex education have been suggested for improving the current practice of sex and sexual health education in Nepalese schools.
\end{abstract}

Key words: Sex education, education, school, adolescence, Nepal

\begin{abstract}
Qexual health education in school is regarded $\checkmark$ as an effective way to increase young people's understanding of Sexually Transmitted Infections (STIs) including HIV (human immunodeficiency virus) infection, unintended pregnancies and abortion, infertility and cancer ${ }^{1}$. Despite limited research evidence of effect on improving sexual health outcomes, young people generally agree that secondary schools are suitable sites for sex education ${ }^{2}$. A range of research evidence also indicates that school-based sex education has potential to prevent unwanted pregnancy and to promote positive sexual health at the individual, family and community or health system level ${ }^{3,4}$.
\end{abstract}

One in five people in the world today are between 1019 years of age and $85 \%$ of them live in developing countries ${ }^{5}$. However, as a group they are not considered a health priority, which has resulted in poor sexual behaviour among them ${ }^{6}$. Sexual and reproductive ill health is one of the major causes of morbidity and mortality among young people ${ }^{7}$. Young people are also at risk of unwanted pregnancies, STIs and unsatisfactory or coerced early sexual relationships ${ }^{8,9,10}$. Despite young people making up a large proportion of the population in developing countries, there is relatively little known about their sexual health, knowledge and experience ${ }^{11,12,13,14}$. Some people have suggested that talking about sex and sexuality to young people could encourage earlier sexual experimentation. However, international evidence consistently reveals that openness and sexual education encourages more sensible and healthy behaviour and may also delay sexual debut ${ }^{15}$.

There is a circular relationship between lack of education, early marriage, low social status and poverty in $\mathrm{Nepa}^{54}$. One report suggests that the age of onset of puberty is decreasing and age at first marriage is increasing ${ }^{16}$. Although, the sex education is a taboo subject in the most part of the country, young people are more likely to be sexually active before marriage than their parents' generation due to the open culture of western modernisation through the globalisation of information ${ }^{17}$. Men who have sex with men (MSM) are also present in Nepal however; culturally determined sexual norms have drawn fewer distinctions between homosexuality and heterosexuality ${ }^{18}$.

Correspondence

Dev Raj Acharya,

Project Assistant

Epidemiology Group, Section of Population Health

School of Medicine \& Dentistry

University of Aberdeen, Foresterhill

Aberdeen, AB25 2ZD, Scotland, UK

E-mail: d.acharya@abdn.ac.uk,devranju@yahoo.com 
The first National Health Strategy was implemented in 1998 and National Adolescents Health and Development Strategy in 2000 in the country ${ }^{19,20,21}$. Based upon this strategy, pupils are taught basic sex education at higher secondary level using the textbook Health, Population and Environment ${ }^{22}$. Teaching sexual health is often very poor, which is directly associated with teacher's embarrassment, lack of knowledge and poor teaching techniques. In addition, teachers are also confused as existing courses are insufficient to address young people's need ${ }^{23,24}$. Nepalese schools evaluate the sex education programme in exam set up which is uncommon in developed countries such as the UK. Apparently, schools examine the more easily taught, less challenging, factual and biological issues where as the broader issues such as feelings and relationships are often being overlooked ${ }^{30}$. Nepalese schools are also involving health professionals and experts to deliver sex education with the support from Non-Government Organizations (NGOs). However, there is a lack of coordination and cooperation between schools and NGOs to share any evaluations and areas that can be improved.

\section{Materials and methods}

This article reviews the literature in developing and delivering sexual health education programmes relevant to Nepalese secondary education. We highlight major challenges and key issues and suggest some possible improvements. Electronic databases such as Medline, CINAHL, Science Direct, Popline, Scopus and Google Scholar were searched to access the journals between 1987 and 2008. Documents published on World Health Organization (WHO), United Nations Population Fund (UNFPA), Ministry of Health $(\mathrm{MoH})$, the National Centre for AIDS and STD Control (NCASC) websites were also accessed to assess relevant reports and papers. Published and unpublished organizational reports, relevant articles and some grey literature were also included in this paper.

\section{Key Issues}

The literature suggests four main issues which can help to improve the quality of school-based sex education in Nepal: (1) limitations to teaching; (2) policy and practice; (3) parental and community support; and (4) research in school-based sex education.

\section{Limitations to teaching}

Education plays a vital role in guiding and changing young people's behaviour ${ }^{16}$ and teachers are the main delivers of sex and reproductive health education in schools. However, very few have received specific training to do $\mathrm{so}^{26}$. Most Nepalese teachers, from both government and private schools, are reluctant to discuss sex education. Improving teachers' training and skills is particularly successful in boosting the confidence of those teachers who think that delivery of sex education curricula as most challenging. Various studies have also recognized that on-going professional development is needed to sustain teachers' confidence in delivering effective sex education ${ }^{27,28,29}$.

There are conflicting interests among teachers, parents and pupils regarding sex education. Teachers in Nepal often deliver biological information, whereas parents are more interested in moral education. Pupils are looking to acquire more insights into life skill-based sex education. Thus, there is a need to consider these interests and to develop teacher training which moves away from superficial biological coverage towards a more inclusive programme ${ }^{30}$. Some teachers consider their pupils to be too young for sex education ${ }^{2}$. However, studies in industrialised countries have highlighted the need to start sex and relationship education at an earlier age, preferably in primary school ${ }^{31,32}$.

The complexities of the relationship between gender and sex education need to be explored, since sexuality, like other aspects of life, work, culture or science is gendered in Nepal. The inequalities which are associated with gender will affect behaviour and attitudes in fundamental ways $^{33}$. One study suggested that girls and boys responded differently to the sex education programmes, and that boys reacted more negatively than girls ${ }^{34}$. Thus, there is a need for better strategies to (a) reach the boys effectively; and (b) maintain the girl's interests.

In addition, there are not enough audiovisual materials to teach sex education programme in Nepalese schools. Teachers have to rely on a textbook which hinders the effective teaching of sex education. It has created an uncomfortable situation for them and they want to do better ${ }^{24}$. In order to achieve the key objectives of sex education, a more positive attitude is needed to develop effective teaching aids.

\section{Existing policy and practice}

Policy initiatives and examinations of sexual health education in Nepal are relatively recent. In this context, the National Reproductive Health Strategy (1998) and the National Adolescent Health and Development Strategy (2000) are important policy documents for sex education $^{19,20,21,22}$. At present there is an evidence of wide variations between schools in the nature and extent of the provision. As a response to better sexual health and response to HIV, sex education should be given a higher profile in government policy and practice ${ }^{35}$.

Premarital and extramarital sex has been discouraged in Nepal and most of the Asian countries ${ }^{36,37}$. Although, 
studies carried out in different geographical settings have shown that unmarried adolescents in Nepal are becoming more sexually active ${ }^{38,39}$. Education about responsible sexual behaviour and specific, clear information about the consequences of sexual intercourse is frequently not offered in the home, at school, or in other community settings in $\mathrm{Nepal}^{40}$. In order to formulate and implement effective health policies and programmes for young people, it is important that the prevalence of highrisk taking behaviour and its contributing factors are identified.

Some argue that outside experts; such as health workers could be more effective and informative than teachers for teaching sex education. Young people also like outsiders if they are trained in a manner to increase their comfort level around discussing sexuality and sexual health ${ }^{41}$. Experts are valued for their technical expertise and their ability to handle embarrassing subjects. Those external experts could take the pressure off teachers when dealing with highly sensitive topics, since they do not have to maintain an ongoing relationship with pupils $^{28}$. Some others emphasize that separate classes for girls and boys improve sex education ${ }^{24}$. However, the current policy framework does not mention the involvement of external agencies nor the idea to teach boys and girls separately. It is widely considered that healthy living should not be limited to the classroom; rather it should be extended beyond it. Schools and authorities should also understand the rights and responsibilities of the parents and young people. Thus, there is a need for appropriate policies to enable the delivery of sex education which educates, enables and protects young people.

\section{Parental and community support}

In Nepal, parents often believe that pupils are too young to discuss sexual issues and that sex education encourages their children to engage in sexual activity ${ }^{37}$. They may try to control their children's behaviour; however young people report having numerous opportunities for planned and unplanned sexual encounters. An earlier study conducted in three districts; Kathmandu, Makwanpur and Chitwan showed that about $20 \%$ of unmarried young people were sexually active of which $16 \%$ reported multiple partners ${ }^{42}$. A comparative study on substance use and pre-marital sex among adolescents (age 15-19), found that protective childhood family characteristics such as growing up with two parents, absence of frequent family conflict and having close relationships with parents tend to decrease the probability of early initiation of sexual intercourse ${ }^{39}$. Moreover, the lack of dialogue between schools and parents in the context of sex education might damage school's reputation in an era of parental choice $^{29}$.
Parental support is the primary need for schools which offer sex education. However, both parents and pupils should be engaged in initiatives to promote respect and responsibility ${ }^{43}$. A study shows that only $7 \%$ boys and $14 \%$ of girls have received information about sex and relationship from their parents ${ }^{44}$. For the parents, delegating sex education to the schools mitigates them of an uncomfortable responsibility which they often feel inadequate to fulfill ${ }^{45}$. Therefore, it is important that schools communicate about sex education with parents, community people and pupils at an early stage.

\section{Review and research in sex education}

Sex education programme in Nepalese schools is generally regarded as worthwhile. However, there are very little research conducted into the quality and effectiveness of sex education, apart from some pilot studies ${ }^{46}$. Various studies and organisational reports suggest that a significant proportion of Nepalese young people are at risk of HIV, have high adolescent fertility and are engaged in high risk behaviour ${ }^{47,48,49}$. However, we do not know to what extent this reported sexual behaviour among young population is representative of all puplis. Schools which do not have a strategic approach to research and evaluation are more unlikely to be consistent in the review and evaluation of sex education programmes ${ }^{31}$.

Nepalese schools need support and encouragement to evaluate the quality and effectiveness of their sex education programme and the acceptability of such programmes to all stakeholders. Although, schools and research organisations wish to conduct research in sex education, there are few resources available, and a high competition for that limited funding. Thus, there is an urgent need for government and research funders to invest in research to address how we can effectively encourage young people to enjoy more fulfilling relationship and choose healthier sexual lifestyles ${ }^{50}$.

\section{Ways forward}

There is no quick fix to resolve the issues listed above. Several studies carried out on school-based sex education in developed and developing world may provide some insight into sex education in Nepal. We address the underlying question: "What can we learn from the available evidence to help make Nepalese school-based sex education programme more effective?"

\section{Diverse methodology in teaching}

It is not enough to give young people relevant sexual health knowledge on the assumption that they will simply choose less risky options. The social world of young people needs to change in order to allow well functioning and safe relationships to be seen as normal and desirable ${ }^{51}$. However, the social reality concerning 
behaviour, and the personal beliefs about that behaviour, constructed in the minds of individual young people, can differ greatly. Therefore, it is not just what is being taught that is important, but how, in what setting and by whom.

Sex and relationship education is a lifelong process through which young people acquire knowledge and skills. It develops beliefs, attitudes and values about their sexuality and relationship within a moral and ethical framework. Schools need to be an open and positive environment for young people to discuss sexual health issues which will be beneficial in developing their sexuality ${ }^{52}$. Effective sex education can help to achieve school's aim of providing accurate and relevant information about the physical and emotional changes that young people and children experience throughout their formative years and into adulthood. Young people want better quality sex education at school which needs to include emotional as well as physical aspects of sexuality ${ }^{53}$. Cultural and psychological impact of sexual relationships also needs to be explored and effective interventions should be implemented.

In a traditional society such as Nepal, many parents fear that sex education would spoil their daughters and may create a problem of finding suitable husbands ${ }^{54}$. Greater access to sex education for girls is a logical step towards delaying childbearing and creating better lives for women. However, a longer period of being single is likely to increase the chance of premarital pregnancy and STIs, especially in an environment in which information and services are not easily available to unmarried girls. Young people need life skills which have a range of personal and interpersonal ability such as assertiveness, communication and decision making skills. These are essential to help young people make informed choices, develop skills relevant to reducing risks, maintain relationship and manage emotions ${ }^{55}$. It is considered as a set of psychosocial competencies that enable young people to think critically about health risks, communicate effectively and make responsible decisions that impact on their health ${ }^{56}$.

Teacher should move from the didactic method of teaching, which is very common in Nepal, and initiate interactive learning, whereby young people are engaged in structured activities or tasks. This encourages them to take part in interaction, provides opportunities to generate and share ideas, challenge one another constructively and explore a range of issues relevant to their lives. Such initiation should be human rightbased, help improve young people's confidence and aspirations, and increase their participation in decision making. The latter refers not only to decision-making around their own sexual health, but also to the wider social and community environments within which young people's sexuality is negotiated ${ }^{57}$. Thus, teachers need to use a more informal approach whereby pupils take more responsibility for their learning and the teacher facilitates rather than 'teaches'. This will allow teachers to take sensitive account of the range of maturity and experience in any class.

\section{Peer educators mobilisation}

Peer-led sex education is currently popular and has been identified as a promising strategy for reducing teenage pregnancy. It is defined as sharing of information, values and behaviours by members of similar age or status group $^{58}$. Common to the principal of peer education is the idea that behaviour is influenced by an individual's social network and the normative values and beliefs that exist among friends, peers and family.

Comparing with traditional teachers-led sex education, the peer-led sessions are often more enjoyable and interactive. The student recognises the peer educators as highly motivated and they are more likely to report that they have learnt something new. Students taking part in peer-led sessions were more able to ask questions and take part in discussions which have modestly improved their sexual behaviour ${ }^{59,60}$. It is found that scripts, carefully developed with young people, which reflect their perceptions, language and experience can help stabilise the quality and fidelity of the learning experiences $^{51}$.

Although peer education is an effective programme strategy, the initial costs of implementing could be high, due to the ongoing need to adequately train, support, and supervise, and equip them with resource material ${ }^{61}$. Further limitations to peer education are that it may be challenging to maintain power relationship and confidentiality with their peers. It may also not always be influential to promote behaviour change on certain topics. Therefore, the influence of status, power, and rank must be considered when designing school-based peer education programmes.

\section{Partnership with parents}

The greater involvement of parent with schools and with teachers can enhance the effectiveness of health education programmes ${ }^{62}$. Parents' participation in the planning of sex education programme is particularly important since their values can influence the young person's attitudes and beliefs. Teachers have to take account of the range of those beliefs, attitudes and values in their pupils. Although, it may not easy to discuss sensitive issues with parents in Nepal, there is a growing body of research which indicates that communication with parents can help delay the age of first intercourse ${ }^{63}$. 
Parents are diverse in terms of beliefs and values, family structure, sexual orientation and parenting styles to their children. Working with parents should reflect these components and make sure that the delivery of information is sufficient. Although, school-board meeting and parent-teacher associations are supposed to be an opportunity to consult with parents, schools need to promote a direct dialogue with them to get their responses ${ }^{28}$. It is important to provide pupils with an education that addresses their reproductive health needs in a holistic manner. It is also useful to develop a parent curriculum that should provide basic reproductive health information to parents and promote better communication between children and parents ${ }^{64}$. Parents should also feel that they have no reason to prevent their children attending any aspect of sex education, and should ensure their continuing attendance.

\section{Role of external agencies and health professionals}

Sex education is a community and family responsibility and should therefore involve the various partners who have different, but complementary roles. Young people need information on sources of health advice, appropriate helplines and access to local sexual health services. Health professionals, who are most accessible to young people and acceptable for schools can provide advice and treatment to young people in a confidential setting. Teachers working with health professionals who have a presence in schools and have built up relationships with young people over time are well recognised and favoured ${ }^{31}$.

However, young people are also more likely to seek advice and information from friends and family than from health professionals ${ }^{2}$. One of the possible reason for this is that pupils worry about being judged and stigmatised during sex education. Thus, health professionals should be adequately trained to meet pupils' needs ${ }^{65}$. Appropriate shared professional protocols with external agencies should also be in place to address pupil's welfare and the rights and responsibilities of parents ${ }^{28}$. Many of the traditional organisations of sexual health and family planning clinics provide contraceptive help and advice. The majority of young people believes that they could be stigmatised using such services. Therefore, young people wish the sexual health services of such organisation to be associated with other services.

\section{Teaching and capacity building}

Delivery method is an important part of teaching and well-trained teachers are critical for quality education. Such educational quality will help to achieve the importance of Sexual and Reproductive Health, which is across all eight UN Millennium Development Goals ${ }^{66}$. It helps to ensure that pupils are being told the facts in a manner relatively abstracted from their lives in broader social contexts. Many teachers are still uneasy about delivering sex education and talking about sex with the pupils. There is evidence that sex education can be ineffective whenever teachers lack confidence and up-to-date knowledge and therefore lose credibility with pupils ${ }^{67}$. It is essential to enhance their own selfefficacy in relation to lesson delivery, before they feel that the new methods in sex education threaten their expertise.

An evaluation of a school-based sex education programme (SHARE) in the UK showed that teacher training developed significant improvement between pre- and post- training, the greatest changes being amongst those with lowest confidence ${ }^{68}$. Many teachers declared that the course to be one of the best training experiences of their careers and $86 \%$ said they were 'very glad' to have attended. Thus, it is important that teachers have particular training and exposure that sensitises them to the importance of the subject matter. It provides them with skills on how to communicate such topic in a manner so that students and teacher both could be benefited ${ }^{69}$.

\section{Support service and access to information}

Difficulties in gaining access to contraception and finding an acceptable method of contraception can contribute to unprotected sexual intercourse among young people. In contrast, proximity to youth-centred services is strongly associated with lower rates of teenage pregnancies ${ }^{70}$. Young people like services which can provide advice and treatment within a confidential setting. It is recognised that sex education programme in secondary schools should include the information about family planning, responsible methods and service of local clinics.

Young people could be reluctant to go to health workers for their sexual health problem. They report that confidentiality, a non-judgemental approach, informality, accessibility, and the ability to choose whether they see a male or female health worker are the most important factors in deciding whether to use services. The health workers therefore, need to be trained to understand young people's sexual behaviour better and maintain confidentiality ${ }^{48}$. It can help to bridge the gap between service providers and young peoples. Most schools and health clinics are open at the same time in Nepal. Thus, young people need to absence their school if they need some sorts of sexual health information and service. Thus, it is crucial to open the sexual health clinics during weekends and school holidays for young people attending school $^{71}$. 


\section{Research and Evaluation}

Knowing where you are, what you can build on and what needs to be improved helps to solve particular, existing problems of sex education. Effective schools are those which do the job by delivering a good quality of sex education to their pupils ${ }^{72}$. Self-evaluation is a reflection on sex education practice in schools which use a quality indicator as the basis for gathering evidence and making evaluative judgements.

A good quality evaluation research on sex education is critical for policy makers and practitioners to understand the needs of sex education and the existing gaps. Such evaluations help schools to identify the need of support by local authority in development and delivery of their policies and findings, and require a realistic amount of time $^{9}$. So far, there has been increase in strong research and advocacy unit in Nepal, and a range of scientific papers has been published from national and global context. Globalised media has also contributed in informing and transferring the best practices on sex education accompanied by the schools in international level. However, government and research funders should invest in discovering how we can effectively and cost-effectively fit such practices in Nepalese context. Therefore, in order to provide greater momentum to sex education in Nepalese schools, more empirical research is needed to establish a clearer picture of the benefits.

\section{Conclusion}

Young people are living in a world of fast and farreaching change, a world of emerging uncertainties in the social, political, technological and economic environments. In this globalised world, the emphasis should be on continuous review and improvement of the quality of sex education, on planning and delivering a better service. It is clear that most Nepalese schools should offer better and more appropriate sex education. Since schools play an important role in informing young people about sexual health matters, there are many areas that need to be improved for the effective sex education. Nepalese schools evaluate the effectiveness of sex education in exam set up, and covers factual and biological issues rather than dealing with feeling and relationships. Sex and sexuality education in Nepalese schools requires further research and evaluation, since it is still very much in its infancy.

Young people are vulnerable to negative sexual health outcomes, and they should be provided with information and skills to reduce such vulnerability. Life-skill based knowledge helps them to take important decisions, especially in the formation of partnerships and in the process of sexual negotiation. Development of multi-agency working to ensure effective and sustainable participation of parents and other external agencies are basic requirements, to seek important guidance and information to improve sex education. Similarly, appropriate training of teachers would benefit comprehensive sex education, as would peer education. The latter would provide young people with opportunities to share their views. It is well documented that sexual relationships are not always mutually desired; in many instances, they are likely to be unsafe, unwanted and coercive. Thus, there is a need to increase access to sexual health services, when needed, to the young people.

\section{References}

1. Gallant M, Maticka-Tyndale E. School-based HIV prevention programmes for African youth. Social Science and Medicine. 2004; 58(7):1337-51.

2. Reeves C, Whitaker R, Parsonage RK, Robinson CA, Swale K, Bayley L. Sexual health services and education: young people's experiences and preferences. Health Education Journal. 2006; 65(4): 368-79.

3. Butler PA. What constitutes sexual health? Progress in Reproductive Health Research [homepage on the internet]. Geneva: World Health Organisation; 2004 [cited 2007 Jul 3]. Available from: http://www.who.int/ reproductive-health/hrp/progress/67.pdf.

4. Saito M. Sex education in school: preventing unwantedpregnancyinadolescents. International Journal of Gynecology \& Obstetrics. 1998; 63:157-60.

5. Keeney GB, Cassata L, McElmurry BJ. Adolescent health and development in nursing and midwifery education. Geneva: World Health Organization; 2004.

6. Bayley O. Improvement of sexual and reproductive health requires focusing on adolescents. Lancet. 2003; 362(9386):830-1.

7. WHO. The second decade: improving adolescent health and development [homepage on the internet]. Geneva: World Health Organisation; 1998 [cited 2008 Nov 4]. Available from: http:// www.popline.org/docs/1328/143704.html.

8. Singh S, Darroch JE. Adolescent pregnancy and childbearing: levels and trends in industrialized countries. Family Planning Perspective. 2000; 32:14-23.

9. Social Exclusion Unit. Teenage pregnancy [homepage on the internet]. London: Stationery Office; [updated 1999; cited 2007 Aug 07]. Available from: www.socialexclusion.gov.uk/ downloaddoc. .asp? $\mathrm{id}=69$.

10. Wight D, Henderson M, Raab G, Abraham C, Buston K, Scott S, et al. Extent of regretted 
sexual intercourse among young teenagers in Scotland: a cross sectional survey. British Medical Journal. 2000; 320:1243-4.

11. Frost JJ, Forrest JD. Understanding the impact of effective teenage pregnancy prevention programmes. Family Planning Perspective. 1995; 27:188-95.

12. Hughes J, McCauley AP. Improving the fit: adolescents' needs and future programmes for sexual reproductive health in developing countries. Studies in Family Planning. 1998; 29:233-45.

13. Oakley A, Fullerton D, Holland J. Behavioural interventions for HIV/AIDS prevention. AIDS. 1995; 9:479-86.

14. NIMH. Methodological overview of a multisite HIV prevention trial for populations at risk for HIV. AIDS, National Institutes of Mental Health. 1997; 11(Suppl.1):S1-S11.

15. Meyrick J, Swann C. An overview of the effectiveness of interventions and programmes aimed at reducing unintended conceptions in young people. London: Health Education Authority; 1998.

16. NDHS. Nepal Demographic and Health Survey. Kathmandu: Ministry of Health and Population, Government of Nepal; 2006.

17. Bhadra RP. A summary of the most important programme directed to issues of youth reproductive health in Nepal. Kathmandu: BP Memorial Health Foundation; 1999.

18. Upadhyay P. Challenge in implementing HIV/ AIDS/STD in prisons in Kathmandu, Nepal. In: AIDS Education Global Information System (AEGiS), editors. Proceedings of the 12th International Conference on AIDS; 1998 June 28-July 3; Geneva, Switzerland: International AIDS Society; 1998. p. 703-4.

19. Campbell BB, Reerink LH, Jenniskens F, Pathak LR. A Framework for developing reproductive health policies and programmes in Nepal. Reproductive Health Matters. 2003; 11(21):171-82.

20. Pradhan A, Strachan M. Adolescent's reproductive health in Nepal: status, policies, programmes and issues. Washington DC: Policy Project; 2003.

21. MOH. National adolescent health and development strategy. Kathmandu: Ministry of Health; Department of Health Service; 2000.

22. MOES. Health, population and environment. Kathmandu: Ministry of Education and Sports, Government of Nepal; 1999.
23. Karki KB. HIV/AIDS Education at schools in Nepal: students, teachers and parents perceptions and preferences. In: AIDS Education Global Information System (AEGiS), editors. Proceedings of the 15th International AIDS Conference; 2004 Jul 11-16; Bangkok, Thailand: International AIDS Society; 2004. p. 310.

24. Pokharel S, Kulczycki A, Shakya S. Schoolbased sex education in western Nepal: uncomfortable for both teachers and students. Reproductive Health Matters. 2006; 14(28):15661.

25. Aryal R, Adhikary U. Adolescent and youth in Nepal in population monograph of Nepal 2001. Kathmandu: National Planning Commission Secretariat; 2003. p. 325-52.

26. Mathur S, Mehta M, Malhotra A. Youth reproductive health in Nepal: is participation the answer [homepage on the internet]. Washington: International Centre for Research on Women; 2004. [cited 2008 Oct 28]. Available from: http://catalog.icrw.org/docs/nepal_0104.pdf.

27. Buston K, Wight D, Hart G, Scott S. Implementation of a teacher-delivered sex education programme: obstacles and facilitating factors. Health Education Research. 2002; 17(1):59-72.

28. McCabe M. Report of the working group on sex education in Scottish schools [homepage on the internet]. Scotland, Edinburgh: Scottish Executive; [updated 2000 June 16; cited 2008 Aug 19]. Available from: http://www.scotland. gov.uk/Resource/Doc/158180/0042808.pdf.

29. Wight D, Scott S. Mandates and constraints on sex education in the east of Scotland. London: Medical Research Council; 1994.

30. Stone N, Ingham R, Simkhada P. Knowledge of sexual health issues among unmarried young people in Nepal. Asia-Pacific Population Journal. 2003; 18(2):33-54.

31. van Teijlingen E, Tucker J, Philip K, Spratt J, Pitchforth E, Imamura $\mathrm{M}$, et al. A review of sex and relationships education in Scottish secondary schools (Full Report) [homepage on the internet]. Edinburgh: Health Scotland; [updated 2008; cited 2008 Oct 21]. Available from: www.healthscotland.com/uploads/ documents/6143-Final-SRE-summaryrep.pdf.

32. Kirby D, Short L, Collins J, Rugg D, Kolbe L, Howard M, et al. School-based programmes to reduce sexual risk behaviours: a review of effectiveness. Public Health Reports. 1994; 109:339-60. 
33. Foucalt M. The history of sexuality; an introduction. Harmondsworth: Penguin; 1981. p. 1.

34. Measor L, Tiffin C, Fry K. Gender and sex education: a study of adolescent response. Gender and Education. 1996; 8:275-88.

35. Mahat G, Scoloveno MA. HIV/AIDS knowledge, attitude and beliefs among Nepalese adolescents. Journal of Advanced Nursing. 2006; 53(5):583-90.

36. Chaudhury RH, Ratne M, Rai V, de Rebello DM, Pradhan B. Socio-economic, demographic and reproductive health profiles of adolescents in SAARC countries [homepage on the internet]. Kathmandu: UNFPA; [updated 1998 July; cited 2008 Nov 01]. Available from: http://www. popline.org/docs/1283/139148.html.

37. Puri MC, Busza J. In forest and factories: sexual behaviour among young migrant workers in Nepal. Culture, Health and Sexuality. 2004; 6(2):145-58.

38. Gubhaju B. Adolescent's reproductive health in Asia. Asia-Pacific Population Journal 2002; 17(4):97-119.

39. Choe M, Hatmadji S, Podhisita C, Raymundo C, Thapa S. Substance use and premarital sex among adolescent in Indonesia, Nepal, the Philippines and Thailand. Asia-Pacific Population Journal. 2004; 19(1):5-26.

40. Dangal G. An update on teenage pregnancy. The Internet Journal of Gynaecology and Obstetrics [serial on the Internet]. 2005; [cited 2008 Aug 15]; 5(1): [about 9 screens]. Available from: http://www.ispub.com/ostia/index.php?xmlPri nter=true \&xmlFilePath=journals/ijgo/vol5n1/ teenage.xml.

41. Teen Sexual Health. Teen sexual health; parents' forum [homepage on the internet]. Vancouver: Vancouver Costal Health; [updated 2008 Oct 7; cited 2008 Oct 14]. Available from: http:// www.vch.ca/teensexualhealth/parents_forum/ parents_forum.htm.

42. Gurubacharya BL, Subedi B. Sexual behaviour patterns in Nepal. Nepal: United Nations Fund for Population Activities; 1992. p. 8.

43. Scottish Executive. Respect and responsibility; sexual health strategy annual report. Edinburgh: Scottish Executive; 2006.

44. Todd J, Currie C, Smith R. Health behaviour of Scottish school children; sexual health in the 1990s, technical report-2. Edinburgh: University of Edinburgh; 1999.

45. Frankham J, MacLure M, Stronach I. Not under my roof: families talking about sex and AIDS. Horsham: Avert; 1992.
46. Prasai DP. Effectiveness of sexuality education program in Palpa district of Nepal. FPAN, Journal of Reproductive Health. 1999; 1(1):612.

47. Sanzero L, Mahat G. Psychological factors in Nepali former commercial sex workers with HIV. Journal of Nursing Scholarship. 2003; 35(1):53-60.

48. Dahal G, Hennink M, Hinde A. Risky sexual behaviour among young men in Nepal; applications and policy working paper (A05/01). England: University of Southampton; 2005.

49. NCASC. Cumulative data of HIV and AIDS. Kathmandu: National Centre for AIDS and STD Control; 2008.

50. Regmi P, Simkhada B, van Teijlingen ER. Sexual and reproductive health status among young people in Nepal: opportunities and barriers for sexual health education and services utilisation. Kathmandu University Medical Journal. 2008; 6(22):248-56.

51. Evans DL, Tripp JH. Sex education; the case for primary prevention and peer education. Current Paediatrics. 2006; 16(2):95-9.

52. Reid M. Teen sexual health advertising post-test research. Edinburgh: Health Education Board of Scotland; 1999.

53. Health Education Authority/BMRB. Sexual health matters survey. London: Health Education Authority; 1998.

54. Waszak C, Thapa S, Davey J. The influence of gender norms on the reproductive health of adolescent in Nepal; perspective of youth. Geneva: World Health Organization; 2003.

55. Magnani R, MacIntyre K, Karim A, Brown L, Hutchinson P, Kaufman C, et al. The impact of life skills education on adolescent sexual risk behaviours in KwasZulu-Natal, South Africa. Journal of Adolescent Health. 2005; 36(4):289304.

56. ESCAP. Young people-partners in HIV/AIDS prevention [homepage on the internet]. New York: United Nations; [cited 2008 June 22]. Available from: http://unescap.org/esid/hds/ pubs/2301/pub2301.pdf.

57. Aggleton P, Campbell C. Working with young people-towards an agenda for sexual health. Sexual and Relationship Therapy. 2000; 15(3):283-96.

58. Sciacca JP. Student peer health education: a powerful yet inexpensive helping strategy. The Peer Facilitator Quarterly. 1987; 5:4-6.

59. Forrest S, Strange V, Oakley A. A comparison of students' evaluations of a peer-delivered sex 
education programme and teacher-led provision. Sex Education. 2002; 2:195-214.

60. Stephenson JM, Strange V, Forrest S, Oakley P, Copas A, Allen A, et al. Pupil-led sex education in England (RIPPLE study): cluster-randomised intervention trial. Lancet. 2004; 364:338-46.

61. Horizons. Peer education and HIV/AIDS-Past experience future directions [homepage on the internet]. Birmingham, USA: Population Council; [cited 2008 Oct 27]. Available from: http://www.popcouncil.org/pdfs/peer_ed.pdf.

62. Perry CL, Luepker RV, Murray DM, Kurth C, Mullis R, Crockett $\mathrm{S}$ et al. Parent involvement with children's health promotion. American Journal of Public Health. 1988;78:11156-60.

63. Dilorio C, Kelly M, Hockenberry-Eaton M. Communication about sexual issues: mothers, fathers and friends. Journal of Adolescent Health. 1999; 24(3):181-9.

64. Thapa S, Davey J, Waszak C, Bhadra R. Reproductive health needs of adolescent and youth in Nepal; insights from a focus-group study. Kathmandu: Family Health International, Population and Reproductive Health; 2001.

65. Jones M. School nursing and standards of care. Nursing Standard. 1990; 4(20):38-9.

66. MDGs. Millennium Development Goals [homepage on the internet]. New York: United Nations; [cited 2008 Oct 2]. Available from: http://www.un.org/special-rep/ohrlls/lldc/ MDGs.pdf.

67. Lowden K, Powney J. External evaluation of two health education programmes. Edinburgh: Scottish Council for Research in Education; 1994.

68. Wight D, Abraham C. From Psycho-social theory to sustainable classroom practice: developing a research-based teacher delivered sex education programme. Health Education Research. 2000;15(1):25-38.

69. Smith G, Kippax S, Aggleton P, Tyrer P. HIV/ AIDS school-based education in selected AsiaPacific countries. Sex Education. 2003; 3(1):321.

70. Diamond I, Clements D, Stone N, Ingham R. Spatial variation in teenage conceptions in south and west England. Journal of the Royal Statistical Society. 1999; 162(3): 273-289.

71. Regmi K. Opportunities and challenges of sexual health services among young people: A study in Nepal. The Journal of Sexual Medicine. 2008; 6(2): 352-361.

72. HM Inspectorate of Education. How good is our school? The journey to excellence [homepage on the internet]. Denholm House, Livingstone: HM Inspectorate of Education; [cited 2008 Oct 28]. Available from: http://www.hmie.gov.uk/ documents/publication/hgiosjte.pdf. 